\title{
A ANÁLISES DAS CITAÇÕES PRECISA DE UMA TEORIA OU DA FILOSOFIA DA CIÊNCIA?!
}

\author{
Maria Nélida González de Gómez*
}

RESUMO: Este trabalho, de cunho epistemológico, visa a reconstruir a busca de explanação teórica das metodologias informêtricas, conforme a abordagem dos pioneiros das teorias da citação e da co-citação. Consideramos que essa auto-reflexão, confrontando diferentes alternativas teóricas, tem sinalizado questões importantes, que podem renovar nossas prioridades de pesquisa, nas atuais encruzilhadas dos estudos da informação.

Palavras-chave: Análise de citações. Small. Paradigmas. Construtivismo. Normas.

\footnotetext{
* Doutora em Comunicação pela Universidade Federal do Rio de Janeiro, Brasil. Docente Permanente do Programa de Pós-Graduação em Ciência da Informação da Universidade Federal Fluminense, Brasil Professora visitante Nacional Senior na Universidade Federal Fluminense, Brasil. Pesquisadora CNPq IA.

E-mail: marianelidagomez@gmail.com.
}

\section{INTRODUÇÃO}

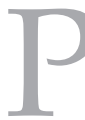
odemos dizer que, desde a modernidade, as formas sociais de construção de evidencias estão fortemente associadas aos regimes vigentes de informação, orientação que se intensifica com a expansão das novas tecnologias de comunicação e informação. De modo preferencial, a definição e implementação dos critérios de valoração e validade do conhecimento científico, tem como uma de suas principais instancias de sustentação e aferimento, um plano regulado e regulatório de ações e recursos de informação (periódicos científicos, bases de dados de indexação, repositórios institucionais).

Os sistemas de informação e de controle bibliográfico, cumprem papeis importante na formação de memórias, na reutilização de resultados e na constituição e manutenção de redes de colaboração de pesquisadores e instituições de pesquisa. Entender o

I Este texto é parte da pesquisa desenvolvida com apoio do CNPqMCTIC. Agradecemos a leitura e observações da Professora Alegria Bechimol. funcionamento e efeitos dessas interações dos sistemas de produção e comunicação de conhecimentos científicos, os sistemas e recursos de informação e os sistemas de avaliação, assunto de preocupação da Ciência da Informação, hoje é objeto de interesse em outras áreas do conhecimento, que vem na revisão por pares e na elaboração de indicadores bibliométricos, casos exemplares das práticas sociais de valoração e avaliação (LAMONT, 2013).

Nos últimos anos, os estudos da informação têm priorizado o desenvolvimento e aplicação de metodologias e inovações tecnológicas, sem problematizar a própria natureza das relações de valor e validação que se estabelecem nas interações da produção e comunicação dos conhecimentos e sua mediação por dispositivos de informação.

Essa ênfase nas metodologias pareceria estar mudando nos últimos tempos, dando lugar a uma produção crítica e reflexiva, da qual são uma boa amostra os livros coletivos editados por Blaise Cronin e Cassidy R. Sugimoto (2014) e Cassidy R. Sugimoto (2016a), e os trabalhos dos pesquisadores da universidade de Leiden (RIJKE 
et al., 2016). Sugimoto (2016b) enumera e categoriza alguns dos principais candidatos às teorias explanatórias da constituição e serventia dos estudos informêtricos: a informetria crítica; a teoria das citações; as teorias estatísticas; as indagações acerca da autoria; as análises empreendidas pelas teorias de organização do conhecimento e as que tratam de desvendar a direção e alcance das altimetrias (SUGIMOTO, 2016b).

Neste trabalho, nosso objetivo é a reconstrução das abordagens que buscam uma explanação teórica da informetria, como uma emanação de uma teoria da ciência, seus agentes e produtos, colocando como condição que os modos de conhecer a ciência sejam compatíveis com as metodologias externalistas e de preferência, respeitando premissas empíricoanalíticas.

Incluímos nessas abordagens as análises de citações e co-citações, seus instrumentos, como os índices de citação, e seus produtos, como os mapas da ciência.

As análises de citações surgiram e foram avaliadas, primeiro, por seu valor heurístico, como ferramentas inovadoras de recuperação da informação, e a seguir, pelo valor historiográfico de suas séries que, objetivadas e mesuráveis, ofereceriam garantias de verificabilidade a reconstrução histórica da ciência. É numa fase posterior e relativamente recente, que serviços e recursos de indexação e controle bibliográfico foram reformulados e modelizados na construção de indicadores de desempenho, e instrumentalizados nos sistemas de avaliação.

Tendo em vista essa trajetória de um dos mais atuais programas de pesquisa informêtrica, nos detivemos nos pioneiros das análises de citações, e perguntamos como eles tem lidado com as demandas de justificação de seus próprios recursos de argumentação. Enfatizamos a particularidade dos discursos informêtricos (cientométricos, bibliométricos) por serem, enquanto reescrita da literatura científica, discursos trans-científicos A partir dos modelos inovadores de representação bibliográfica e documentária, têm construído um novo plano de representação da ciência cuja relevância vai exceder os interesses instrumentais e historiográficos, gerando um valor estratégico na esfera da gestão e da política científica, sobretudo em cenários de competição. Conforme Small, 2003:
Meu objetivo era aplicar a metodologia de cocitação em todas as ciências para que a estrutura completa pudesse ser vista em um único mapa. Derek Price (1986) referiu-se a isto como o mapa de guerra da ciência, e ele imaginou uma sala onde os burocratas do governo monitorassem uma grande exibição do terreno científico planejando sua próxima manobra. (SMALL, 2003, p 395, Tradução e grifo nosso).

O uso de indicadores de desempenhos com base das análises de citações e co-citações, não é totalmente alheio as expectativas de Price.

Neste trabalho, optamos por acompanhar alguns dos pioneiros da análise de citações, não somente porque se trata de uma área que tem ganhado espaço nos sistemas atuais de avaliação e na elaboração de indicadores de desempenho, mas porque em seus mais de 60 anos de desenvolvimento (GARFIELD, 1955), tem gerado um programa de pesquisa produtivo, com altos investimentos na concepção de modelos e metodologias, mas também prolífero em debates e na geração de fóruns de reflexão, com certas preocupação com os aspectos normativos, oferecendo um rico material para a reconstrução das demandas e do funcionamento (ou não) das teorias.

A partir dos estudos e inquietações de Garfield, a análise de citações iniciava uma nova modalidade de representação da ciência, multidisciplinar e com perspectivas de séries de longa duração, com a intenção de aprimorar os instrumentos de indexação, para ele, até então inconsistentes, sem coordenação, e demarcados pelas disciplinas. Small $(2003,2016)$ desenvolve abordagens reflexivos e problematizadores, ao mesmo tempo em que mantém um forte envolvimento com as aplicações experimentais e funcionais das metodologias de análises das citações. Reconstruímos assim as perguntas e os caminhos argumentativos recorridos por esses dois autores: a saber, se essa teoria das citações seria, sem mais, uma teoria da ciência.

Sem deixar de ter traços comuns com suas primeiras fases, a retomada e expansão das análises de citações, em torno do ano 2000, terá um perfil próprio, associado a proliferação de indicadores de desempenho, instrumentalizados nos grandes sistemas de avaliação da ciência e da academia, atendendo às demandas de prestação de contas de agências governamentais 
de monitoração e credenciamento, e em geral, das agências de fomento. Para muitos, a expansão da informetria e a formulação e uso crescente de indicadores de desempenho seriam impulsionados pelas tendências econômicas e políticas neoliberais, que estimulam a adoção das estratégias de gestão empresarial nas esferas do Estado. Nesse nicho de demandas estariam alocados os dispositivos algorítmicos formatados por modelos informétricos.

Manteremos nossa análise no domínio investigativo dos pioneiros das análises de citação, esperando que ela ofereça alguns indícios ou perspectivas de generalização.

\section{O OTIMISMO EPISTEMOLÓGICO DOS PIONEIROS}

Em 1955, Garfield publica em Science sua proposta de criação de um índice de citações reunindo suas próprias pesquisas, a descoberta inspiradora de um instrumento elaborado por juristas e profissionais do Direito, nos Estados Unidos.

\begin{abstract}
A ideia de um índice de citação para a ciência foi $\circ$ ponto culminante da investigação do autor sobre as características lingüísticas e de indexação dos artigos de revisão científica e um encontro serendipítico com as Citações de Shepard. Ambas estas inspirações resultaram das interações com acadêmicos reconhecidos. Meu interesse inicial, que logo se tornou uma preocupação, foi despertado pelo farmacologista / historiador Chauncey D. Leake (Garfield, 1970, Garfield, 1978). Minha introdução ao sistema legal de citação dos Estados Unidos veio de um vice-presidente aposentado das Citações de Shepard, WC Adair (Adair, 1955), que me escreveu em março de 1953, no final do Projeto de Indexação Médica Welch, da Johns Hopkins. (GARFIELD, 1998, p.68, Tradução nossa).
\end{abstract}

Em torno dos anos 60 e 70, as representações e as análises da produção científica a partir das citações, foram alavancadas por um duplo otimismo epistêmico: por um lado, por gerar expectativas de inovação nos mecanismos de recuperação da informação; por outro, por ser um instrumento de reconstrução histórica e verificabilidade historiográfica, já que as associações reiteradas de autores e conceitos, objetivadas pelas referencias e citações, dariam visibilidade a formação de padrões recorrentes num domínio de conhecimento. Os pioneiros da análise de citações, não teriam duvidado de seu valor heurístico, sustentando expectativas de um conhecimento objetivo e objetivável da produção científica.

Garfield tinha reunido as disponibilidades matemático-computacionais das emergentes bases de dados com técnicas padronizadas da escrita científica, a citação e a referência, formalizadas pelos padrões de controle bibliográfico. O imaginário científico-tecnológico daria corpo a uma ideia que, num futuro próximo, forneceria importantes recursos à governamentalização das ciências e ao crescimento das indústrias e dos negócios da informação, o índice de citação. Como ponto de partida de sua inovação, Garfield teria o apoio de uma analogia epistêmica: "[...] se consideramos o livro como a macro unidade do pensamento e o periódico como microunidade, logo o índice de citação em alguns aspectos trata das unidades do pensamento sub-micro ou moleculares" (GARFIELD, 2006, p.1123).

Dando um passo a mais, além de ter identificado e afirmado uma equivalência entre uma unidade molecular do pensamento e a "string" de palavras que compõem o texto de uma citação, Garfield "domesticou" o algoritmo das bases de dados referenciais para elas assumirem a tarefa específica da montagem dos índices de citação.

Legitimando o achado, Merton (1979) justifica o uso sistemático da citação e a referência, como expressão de um princípio da economia da ciência: quanto mais um cientista coloca sua produção intelectual no domínio público (e só assim), mais ela será reconhecida como sendo de sua autoria (sua propriedade), e mais poderá ser reconhecida pelos pares.

Podemos começar com um aspecto da estrutura latente social e cultural da ciência pressuposta pela evolução histórica do uso sistemático de referências e citações nos artigos e nos livros científicos. Esse aspecto é - caráter aparentemente paradoxal da propriedade no empreendimento científico: a circunstância de que, quanto mais amplamente os cientistas 
disponibilizam sua propriedade intelectual livremente a outros, com mais certeza ela chegará a ser identificada como sua propriedade. Porque a ciência é conhecimento público e não privado. Só com a publicação do seu trabalho os cientistas podem fazer a sua contribuição (como diz a própria palavra) e só quando ela se torna parte do domínio público da ciência podem verdadeiramente reivindicá-la como sua. [...]. E, em geral, - trabalho científico é estimado na medida em que outros podem recorrer a ele para avançar em sua própria futura investigação. (MERTON, 1979, s/p, tradução e grifo nosso)

Para Merton (1979), esse modo de distribuição dos excedentes da produção científica não é um traço natural da espécie humana, nem um comportamento altruísta: seria o resultado de arranjos institucionalizados pelos quais os pesquisadores, ao contribuir livremente para a construção de uma riqueza comum, conforme suas capacidades, podem também usarse dessas riquezas quando precisarem. Tratar-seia de uma generalização da instituição científica antes que de uma premissa epistemológica a priori, de vigência universal.

Citações e referências operam,
portanto, dentro de uma estrutura
conjunta cognitiva e moral. Em seu
aspecto cognitivo, eles são projetados
para fornecer a linhagem histórica
do conhecimento e para orientar
os leitores do novo trabalho para
as fontes que eles podem querer
verificar ou aproveitar para si. Em seu
aspecto moral, eles são projetados
para reembolsar dívidas intelectuais na
única forma em que isso pode ser feito:
através do reconhecimento aberto delas.
Tal reembolso não é uma exigência
normativa menor. Isso é evidente a
partir das sanções morais e, por vezes,
legais, sobre aqueles que se julga ter
violado a norma, através dos tipos do
grande e pequeno furto intelectual, que
conhecemos como plágio. (MERTON,
I979, s/p)

Tanto as apostas mertoneanas (validade e validação baseadas em normas) como os modelos cientométricos (construídos sobre operações associativas mediadas por algoritmos) têm sido objeto de adesões e críticas. Nesse quadro, Garfield, em sua narrativa sobre o desenvolvimento do Science Citation Index, adota uma postura ponderada.

Ao longo de seus textos, produzidos durante mais de 50 anos, Garfield tem mantido sua convicção sobre a forte equivalência ou analogia das configurações da ciência e de sua representação num recurso de informação, o índice de citações. O Science Citation Index teria gerado um corpus organizado de milhões de referências vinculadas pela citação, em séries temporais cada vez mais extensas, permitindo a reconstrução histórica dos programas de pesquisa e das vinculações, de extensão indefinida, mas comprovável, que os incluem e os legitimam. $\mathrm{O}$ recurso algorítmico agregava valor a indexação, atendendo a crescentes demandas de eficiência, rapidez e padronização dos procedimentos. Garfield manteve sempre em aberto a pergunta pelo alcance e validade dessas construções, visando a esclarecer os limites e condições de sua eficácia epistêmica. Corrobora, assim, a abordagem da análise de citação de Cornelius Le Pair (1995): “A análise de citação é uma ferramenta de avaliação justa para os subcampos científicos em que o principal veículo de comunicação é a publicação em literatura serial (Le Pair, 1995)". (GARFIELD, 1998, p 67, Tradução e grifo nosso).

Em seu texto de 1978, Small afirma que os documentos citados eram símbolos de conceitos, sinalizando o funcionamento da citação e da referência como indicadores de redes de colaboração da ciência. Se a "referência" dá visibilidade à indexicalidade do documento, situando-o no universo-rede das publicações científicas, a "citação" coloca em evidência os nexos argumentativos do discurso público da ciência, situando-os no universo dos conhecimentos socialmente certificados e disponíveis.

Small (2003) teria buscado, primeiro, na coocorrência de palavras um indício dos processos de formação de conceitos, estabelecendo equivalências entre a sequência das palavras e sua vinculação semântica na expressão de uma ideia. Ao conhecer o índice de citação, Small (1980, 2003) reconhece que a citação oferece um princípio de articulação mais forte que a sequência reiterada de palavras, já que o ato autoral da citação estabelecia vínculos conceituais duplamente garantidos: pelas normas sociais mertoneanas e pelos padrões de referenciação da comunicação científica. 
Co-citações agregadas, poderiam funcionar como recursos de visualização das dinâmicas das pesquisas e seus direcionamentos progressivos (ou não), e por isso, poderiam considerar-se como vereditores da qualidade da produção científica e de sua posição na composição das frentes da pesquisa.

\section{SMALL CITAÇÕES E REFERÊNCIAS, COMO TESTEMUNHOS HISTORIOGRÁFICOS}

Nas análises de citação, a reconstrução de cadeias indexais e a mensuração de frequências de ocorrência de seus componentes, requer a agregação seletiva de informações, conforme " $n$ " critérios e finalidades de escolha e representação (ex: quais periódicos, com que abrangência temática, linguística, institucional). As redes indexadas de referências e citações, geram novas "textualidades" que são direcionadas a novos contextos de interpretação (administrativos, avaliativos, meta-científicos), e tem ido ganhando maior grau de independência com respeito aos contextos primários das atividades de produção e comunicação em ciência e tecnologia.

Qual é a relação desses artefatos literários e algorítmicos (enquanto obtidos pelo processamento e transformação da escrita da ciência) com a verificação de hipóteses acerca de estados de coisas num "mundo real", ou com a previsão do rumo progressivo de um programa de pesquisas científicas?

Para Wouters (1999, 2014), as citações e referências dos discursos científicos são diferentes da composição, em bases de dados, das representações indexadas daquelas citações e cocitações; justamente por tratar-se de expressões linguísticas com diferentes referências, remetem a diferentes ordens ontológicas (SUGIMOTO, 2016b, p 4).

Small $(2003,2016)$, tem seguido seu próprio caminho de indagação mantendo a robustez de seus argumentos e a lisura de suas reflexões: uma vez convicto da potência heurística das citações, como domínio e instrumento de pesquisa, procura esclarecer e legitimar os elos de periódicos e artigos científicos e as práticas de pesquisa, de modo que algum critério de validade epistêmica possa alavancar primeiro a validade epistêmica da publicação científica e logo, o índice de citações e a análise de co-citações, como componentes eficazes e produtivos das aventuras históricas da ciência.

$\mathrm{Na}$ obra de Small, identificamos dois textos que são expressivos de diferentes questões, lançadas desde uma mesma problematização: no primeiro, faz um revisão crítica das proposições de Kuhn sobre a história da ciência (SMALL, 2003); no segundo (SMALL, 2016), aborda as abordagens construtivistas e normativistas da ciência, tendo como objeto único de preocupação justificar demandas de validação, ao mesmo tempo, do conhecimento científico e da escrita padronizada da ciência. Encontra, nesse rumo, a abordagem normativa da ciência de Merton (1973) e Zuckerman (1977, citado por SMALL); recorre ao apoio adicional das teorias evolutivas, buscando afiançar comportamentos de colaboração, e sua expressão nos contextos normativos da ciência, numa constante antropológica genérica (SMALL, 2016).

Small (2003), interessado na história da ciência (estudou com Kuhn), encontra um importante potencial historiográfico nos índices de citação, capazes de proporcionar recursos descritivos e heurísticos para reconstruir grandes mapas da produção científica. O uso da metáfora espacial remetia à uma representação não mentalista nem idealizada da ciência. Sendo os artigos científicos, estabilizados por padrões bibliográficos e certificados pelas comunidades e instituições da comunicação científica formal, conforme os cânones sociais e técnicos de um domínio, os corpus de citações e co-citações extraídos desses artigos teriam um grau de credibilidade e do valor referencial equivalente as das fontes de origem de suas representações. Para Small (2003), citações e referências ofereceriam uma boa oportunidade de tradução empírica dos paradigmas de Kuhn, sendo um meio para sua visualização:

\footnotetext{
Como doutorando na história da ciência, fui profundamente influenciado pela visão "estrutural" do desenvolvimento científico de Thomas Kuhn (Kuhn, 1970), e mapear um campo parecia de algum modo relacionado ao seu conceito de paradigma. (SMALL, 2003, p 394, tradução e grifo nosso).
}

Com a serenidade de quem deixou sua marca autoral nas realizações contemporâneas 
dos estudos da ciência e da informação, em seu texto Paradigms, citations, and maps of science: A personal history (2003), Small atribui a sua participação nas práticas descritivas da pesquisa histórica, a busca de formas de representação visual e contextualizada das teias de relações e transformações que levam à constituição de um domínio científico (SMALL, 2003). A metáfora espacial redesenhava a metáfora estrutural dos paradigmas. Naquele texto, Small (2003) perguntas pela possível correlação entre $o$ núcleo paradigmático (core), de Kuhn (1962), e a captura de núcleos de excelência, pelas metodologias de construção de mapas de co-citações, assim como a corroboração (ou não) pela análise de citações e co-citações, da teoria das Revoluções científicas.

Para Small, uma vantagem adicional da análise de citações, seria a simplificação metodológica da pesquisa, ao substituir, no ponto de partida, os corpus volumosos de documentos primários por sínteses geradas pelos índices de citações, sob a pressuposição de uma analogia entre elementos bibliográficos (como citações e referências) e conceitos, enquanto valores semânticos compartilhados (SMALL, 2003, p 394). Resultados obtidos com a utilização do SCI validariam essas premissas: “[... ]para minha surpresa, os padrões no SCI foram muito mais fortes do que o que eu tinha visto em minhas amostras históricas". (SMALL, 2003, p 395, tradução e grifo nosso).

Ao mesmo tempo, os documentos mais citados frequentemente estavam vinculados entre si por co-citações, de modo que a quantidade de citações e co-citações teria certa equivalência com o grau em que conceitos ou teorias científicas eram compartilhadas e reconhecidas pelos pares: "Mais tarde, percebi que as citações eram simbolos de conceito mais potentes do que palavras, porque a alta taxa de citação refletia, ainda que imperfeitamente, o reconhecimento de pares (Kaplan, 1965)". (SMALL, 2003, p 395, Tradução e grifo nosso)

Kuhn (1962) e Small (2003), não entendiam do mesmo modo em que consiste uma boa descrição das matrizes epistêmicas da ciência. Para Small (2003), existem relações de equivalência entre as relações (associativas) obtidas a partir das co-citações, e as configurações (estruturantes) dos paradigmas, analogia mais fácil de estabelecer quando as matrizes epistêmicas são representadas por exemplares.
Para Kuhn (1962, entre outros), conforme o próprio Small, as citações só poderiam compor inventários da produção científica.

Small parte assim das referências historiográficas de Kuhn, mas faz uma nova proposta, substituindo o desenho estrutural dos paradigmas pelo princípio descritivo dos mapas da ciência. No texto de 2003, a revisão de suas diferenças com as abordagens de Kuhn são ao mesmo tempo uma ocasião para Small apresentar, de maneira argumentativa, seus esforços de elaboração uma teoria da citação que validara seus créditos por sua complementaridade com uma teoria da ciência.

Outra das questões levantadas por Small, refere-se à tese da descontinuidade histórica da pesquisa e a aceitação, por Kuhn (1962), da teses pós-empiricista da incomensurabilidade das teorias e dos discursos da ciência, presentes na Teoria das Revoluções científicas (KUHN, 1962). Small, neste ponto, se mostraria próximo da "teoria dos jogos de linguagem, do segundo Wittgenstein (1994): assim como as gramáticas wittgensteinianas, transvasam e articulam os jogos diferenciais da linguagem, os mapas de co-citações, numa figuração espacial de relações epistêmicas, dariam visibilidade a vinculações dos conhecimentos produzidos em diferentes tempos, países, disciplinas.

Desde outra perspectiva, Small aponta as dificuldades de operacionalizar as definições kuhneanas dos paradigmas. A ênfase no papel da comunidade que compartilha um paradigma, não avança em termos de descrições que permitam a reconstrução concreta das comunidades de práticas.

\begin{abstract}
Ele observou que as comunidades de uma especialidade poderiam ser identificadas através do estudo da comunicação, tais como referências na literatura ou comunicações informais entre cientistas, mas se contentava em deixar os detalhes para os outros. Devido à imprecisão da definição, os paradigmas têm permanecido principalmente como uma construção filosófica, e para a maioria dos historiadores, algo tão esquivo como unicórnios. (SMALL, 2003, p 394, tradução e grifo nosso).
\end{abstract}

Small observa que o conceito de exemplar, oferecido por Kuhn como alternativa do conceito de matriz disciplinar, parecia mais adequado para 
ancorar a construção do objeto de uma pesquisa empírica, ao associar a figura de cluster à forma empírica de manifestação dos "exemplares paradigmáticos": seria possível atribuir a figura de um cluster aos agregados associativos das análises de citações: "Kuhn (1977) também havia sugerido que exemplares formariam clusters, que ele ilustrou por bandadas [gaggles] de gansos, cisnes e patos". (SMALL, 2003, p 395, tradução e grifado nosso).

Kuhn, a sua vez, agrega outras objeções a sua afirmação de não equivalência entre os paradigmas e os agregados associativos das co-citações. Kuhn refere-se ao fato de que a análise de citação focaliza os artigos e autores mais citados (uma elite das comunidades de reconhecimento), mas não define nem recupera $a$ comunidade total de pesquisadores envolvidos num assunto (SMALL, 2003, p 394-395; tradução e grifo nosso). Não existe critério ou fórmula para calcular e valorar as dimensões da classe da exclusão.

Small considera central a diferença do modo de entender em que consiste o 'inventário' da produção científica de uma especialidade e o que se define como 'paradigma', ao ponto em que "[...] é improvável que Kuhn tivesse aceitado qualquer das nossas reinterpretações bibliométricas de sua teoria". (SMALL, 2003, p 395). A pesar disso, mantém sua convicção de que existiria uma aproximação tão forte como possível entre documentos altamente citados e os clusters de exemplares que são a manifestação de um paradigma.

É claro que qualquer uso de dados de citações pode ser apenas uma aproximação à noção multifacetada original de paradigma de Kuhn. Muito possivelmente, no entanto, documentos altamente citados são tão próximos a seus exemplares ("realizações passadas exemplares") como a ciência da informação pode obter. Ele havia afirmado que os exemplares incluíam [...] ao menos algumas das soluções de problemas técnicos encontrados na literatura periódica. (Kuhn, 1970, p.187).

melhor que podemos esperar dos modelos bibliométricos é um reflexo parcial e imperfeito, como diria Griffith ( 1979), um "espelho falho" da ciência. (SMALL, 2003, 396, tradução e grifo nosso).
Conforme esse otimismo epistemológico, o espelho informétricos que segue a ordem do sucesso (os artigos, autores e periódicos mais citados, por exemplo), não pareceria ter sombra nem ponto cego. Poderia acontecer, porém, que as melhores questões, hipóteses, testes, aplicações, estivessem fora dessa zona de iluminação? Poderia ser que artigos, autores, periódicos não citados, nunca ou pouco citados, tiveram algo importante a dizer, sobre um problema científico e suas soluções? Poderia ser que um conhecimento, aspecto ou modo de conhecer, de valor epistêmico importante, não se manifestasse em palavras nem chegara às publicações?

Outro ponto crítico das abordagens historiográficas de Kuhn e Small, seria a rejeição de Kuhn de toda concepção teleológica da démarche da ciência. Se difere de Kuhn, nesse aspecto, coincide com os autores pós-empiricista na sustentação dos métodos externalistas de abordagem da ciência: Small tampouco aceitaria as versões apriorísticas da unidade da ciência sustentadas pelas epistemologias prescritivas. Seu objetivo de compor "um mapa único da ciência", se realizaria como a projeção visual da reunião, a posteriore, de indícios e ocorrências registradas das interações (indiretas) de pessoas e palavras, ancorados nos arcabouços normativos da pesquisa e dos controles bibliográficos. Mapa sempre mapa provisório, dinâmico e temporal.

A garantia de passagem dos agregados de citações à reconstrução (ou previsão) de agregados de eventos científicos exemplares, como plausíveis de constituir o núcleo de um paradigma, tem como pressuposição a confiança na traductibilidade linguística das referências pelos conteúdos semânticos das citações textuais: nesse entendimento, as citações seriam os elos de intermediação entre marcadores meta-informacionais, estipulados em códigos bibliográficos, e textos na linguagem especializada de um campo disciplinar, elos cruzados na ponte discursiva do artigo científico. A pesar das reticências de Kuhn, sobre a traductibilidade em palavras de um paradigma (lembremos a importância que Kuhn (1962) atribui ao conhecimento tácito e incorporado), para Small (1980, 2003), a reconstrução linguística de um paradigma seria possível e útil: 
Eu mostrei como os laços de cocitação individuais poderiam ser traduzidos em afirmações científicas, e um conjunto de tais laços podem ser vistos como uma rede interligada de declarações. Os textos dos documentos citados foram analisados perto do ponto de citação, o chamado contexto de cocitação, e foi obtido um padrão consensual de uso da linguagem entre vários autores citados. A tradução dos clusters paradigmáticos num discurso científico, esperançosamente, facilitaria o caminho para um novo tipo de serviço de informação especializada (GARFIELD, 1983). (SMALL, 2003, 396, tradução e grifo nosso)

Cabe lembrar que a análise de citações e cocitações, tem como ponto de partida, a ocorrência de atos enunciativos autorais, envolvendo assim algum compromisso ilocucionário com seus conteúdos. Nessa perspectiva a análise das co-citações não só daria visibilidade aos elos e estruturação de redes intertextuais e intertemáticas do conhecimento científico, mas desvendaria, ao mesmo tempo, redes transsubjetivas de formação de consenso.

\begin{abstract}
Claramente, os dados de citações forneciam um mecanismo único para estabelecer conexões consensuais, seja através das historiografias de Garfield (Garfield, Shar, \& Torpie, 1964), de Kessler (1963) ou de cocitation (Small, 1973). O agrupamento e a ordenação destas relações permitiram que a análise se movesse para além das ligações em pares para uma análise estrutural e temática agregada.( SMALL, 2003, p 396, tradução e grifo nosso).
\end{abstract}

Perguntar pela natureza epistêmica da citação e co-citação, como modus cognoscendi da produção extensa dos conhecimentos científicos, implicaria elucidar o modus operandi dos sistemas e recursos de informação (indexação, bases de dados de citações, mapas da ciência), na construção trans-subjetiva de consenso.

Conforme a proposta de Small (2003), de reconstrução meta-discursiva da démarche da ciência, num esforço continuado de coleta e tratamento das marcas bibliográficas e indexais das publicações científicas, seria tal alcance e extensão que a autoria dos pesquisadores seria sobre determinada por um meta-autor, quiçá o gestor algorítmico das grandes bases de dados. Como manter, além de um processo de "switching" automatizável e através de "marcas" indiretas, a vigência de processos sociais e linguísticos de formação de consenso? (SMALL, 2003, 2016).

Para Small (2003), a démarche da ciência é evolutiva, e não revolucionária, mas sem alinhamentos fixos e previsíveis. Os mapas anuais de co-citações permitem reconstruir, com o recurso a uma dupla leitura do tempo, as linhas da inovação (as "frentes da pesquisa" e seus sequenciamentos hierárquicos) e as linhas de continuidade (nos longos prazos, a démarche evolutiva da ciência):

Comparações de mapas anuais
mostraram uma mudança considerável
no micro-nível com a continuidade,
no entanto, em certas características
estruturais em grande escala, tais
como a localização relativa das
principais disciplinas (SMALL, 1993).
A metodologia evoluiu para agregar
frentes de pesquisa singulares em
uma estrutura hierárquica (SMALL \&
SWEENEY, I985), usando os elos mais
fortes para formar especialidades e os
mais fracos para unir as especialidades
em uma rede interdisciplinar. Os laços
interdisciplinares fracos eram a cola
que manteve a estrutura junto. Apesar
da alta rotatividade de documentos, as
disciplinas pendiam juntas em uma teia
frágil.( SMALL, 2003, p 396 , tradução e
grifo nosso)

No desenvolvimento de sua tese, Small afirma que a mudança revolucionária de um campo científico, não poderia detectar-se pelo surgimento de novos clusters, por agregação de documentos; para afirmar a existência de uma ruptura revolucionária, seriam necessárias duas condições: a) que um conjunto de documentos seja substituído por outros, o que indicaria a derrubada do antigo ponto de vista; b) que existam evidencias da continuidade do novo ponto de vista com o estado prévio do campo, no qual e para o qual se constituiria o corte epistêmico: caso contrário, seria um novo campo, um campo emergente, e não a substituição revolucionária de um velho paradigma (SMALL, 2003, p. 396). O conceito de índice de estabilidade, tem a função de medir o grau e natureza da mudança entre dois frentes de pesquisa:" Seguindo o critério usado em um estudo anterior (SMALL, 1977), definimos um "indice de estabilidade" como o número de artigos 
altamente citados, divididos pelo tamanho da união das frentes anterior e posterior". (SMALL, 2003, p 396, tradução e grifo nosso).

Parece interessante constatar que a definição do valor de um índice de estabilidade estaria duplamente condicionada pela normalização dos dados a ser objeto de comparação, a) pelas normas do controle bibliográfico e b) pelas normas sociais e técnicas do domínio da pesquisa. Esses funcionamentos -implícitos ou explícitos- das normas, serão focalizados por Small, em novos trabalhos (SMALL, 2016).

Small (2003), considera que é possível deslizar-se "sistematicamente, documento por documento" (com o apoio das sequencias material e simbólica da publicação científica), mediante as duas maneiras de cruzar as fronteiras das ciências: as especialidades, que transcendem seus limites através de temas compartilhados, como "extensões incrementais"; a interdisciplinaridade, que opera por analogias e dando "saltos imaginativos". Para o autor, "A exploração desses caminhos levanta questões filosóficas intrigantes sobre como diferentes dominios de conhecimento estão conectados, o que E.O. Wilson (1998) chama a consiliência da ciência". (SMALL, 2003, p 396, tradução e grifo nosso).

\section{OUTRO CAMINHO: a reformulação de uma teoria normativa da ciência?}

Retomando a questão da validade dos instrumentos informétricos e especificamente, da análise de citações, como modus cognoscendi da produção científica, num trabalho posterior, Small (2016), sempre na perspectiva de encontrar uma teoria da ciência que forneça uma justificação teórica para a análise de citações, analisa duas abordagens contemporâneas, que manteriam um acirrado conflito: uma, a visão normativa da ciência, mertoneana, vinculada ao otimismo do realismo epistemológico; outra, a visão construtivista, que alguns associam às tendencias pós-modernistas. Tomando como ponto de partida uma análise de Cronin (1984, citado por SMALL, 2016, p49), Small trata de superar essa dicotomia com recurso ao realismo epistemológico e das teorias evoluticionistas.

$\mathrm{Na}$ categoria "construtivista", Small agregaria as concepções sobre a ciência ditas pós-modernas e as abordagens antropológicas dos estudos da ciência, onde agrega os estudos sociais da ciência da escola de Edinburgo, os trabalhos da teoria ator-rede, de Bruno Latour (1998), e os aportes de Knorr-Cettina (1991, citação de SMALL). De maneira resumida, as principais teses construtivistas, do ponto de vista de Small, seriam: A ciência não tem acesso direto ao mundo exterior (tesis anti-realista); o conhecimento é relativo às matrizes e contextos de sua concepção, e isso implicaria que não se pode estabelecer que uma das perspectivas acerca do mundo seja melhor que outra, nem o conhecimento científico seria superior a qualquer outro sistema de crenças; o artigo científico seria o recurso do laboratório para persuadir cientistas e a sociedade em geral da validade de suas afirmações, e sua finalidade seria principalmente retórica: As citações e referências, conforme Latour, seriam parte de um jogo concorrencial de "reforço dos aliados e enfraquecimento dos inimigos", sem necessário impacto sobre os futuros desenvolvimentos da ciência (LATOUR, 1987, na leitura de SMALL, 2016, p 52).

Em sínteses, Small identifica o construtivismo com uma posição epistemológica não realista e uma concepção retórica da literatura científica, na qual a escrita científica e o artigo não teriam nenhuma conexão necessária, lógica ou empírica, com as capacidades heurísticas (ou não) do laboratório, assim como as práticas de pesquisa não garantem evidencias que se permitiriam diferenciar quais as teorias mais ou menos fidedignas, acerca do mundo real.

Neste ponto, a fim de melhor ponderar às teses do construtivismo, recorremos a outra concepção epistêmica, onde nos parece ter bastante clareza a diferenciação da tese da participação ativa do ser humano na geração de conhecimentos $\mathrm{e}$ as teses radicalizadas do antirrealismo. Floridi (2011) pode ilustrar a dupla escolha por uma epistemologia crítica realista e uma concepção demiúrgica do homem, como agente de concepção e de transformação dos modos de conhecer. Para Floridi, se trata, sobretudo, de descartar o que denomina o dogma de Platão, e sua concepção mimética do conhecimento, que faz do homem um receptor ou um usuário do conhecimento. Isto implica em desfazer a ruptura platônica entre poiesis e episteme, e resistir à radicalização 
de categorizações excludentes, que acirram o conflito realistas versus construtivistas.

\begin{abstract}
O risco é fomentar uma cultura epistemológica de receptores e consumidores passivos de informação e não de produtores críticos e proativos de informação. ... esta é uma estratégia infrutífera adotada pelo idealismo romântico e pelo construtivismo pósmoderno....a escolha é erroneamente reduzida a estar negando ou i) qualquer valor poiético para nossas atividades epistêmicas ou ii) qualquer existência, ou pelo menos independência ontológica, para o mundo exterior. (FLORIDI, 20I I, p 5, Tradução nossa)
\end{abstract}

Em contraposição, Floridi apresenta sua versão do construcionismo, ancorado numa filosofia da informação:

\begin{abstract}
O construcionismo é uma abordagem muito comum e não problemática em todas aquelas ciências que têm uma atitude poiética em relação ao seu sujeito, que tendem não apenas a estudar, mas também a construir, como a ciência da computação, a economia ou a ciência política. ...Platão estava certo em definir alguém que sabe (o dialético) como a pessoa "que sabe como fazer e responder as perguntas" (Crátilo, 390c). Ele estava errado em identificar aquele conhecedor com o usuário da informação e não seu fabricante. (FLORIDI, 2017, p 30, Tradução e grifo nosso)
\end{abstract}

Para o naturalismo, a ontologia (o que Floridi entende como descrição de um sistema) teria prioridade sobre a epistemologia (o que o autor denomina modelagem do sistema). A interpretação do naturalismo vai de encontro, aliás, ao senso comum e às teorias da verdade como correspondência. $\mathrm{O}$ não-naturalismo daria prioridade à epistemologia, posição que seria também um dos pontos de partida do construcionismo.

O naturalismo no todo, para Floridi, seria contra intuitivo. $\mathrm{O}$ argumento em que o autor sustenta seu realismo não-naturalista, é que numa explicação pretensamente naturalista, se está deixando fora um excedente informacional, que não tem nenhuma informação referencialidade sobre a ordem da natureza:

De acordo com o não-naturalismo semântico e normativo (também conhecido como moral ou ético), os fenômenos normativos e semânticos não são naturalistas porque sua explicação não pode ser fornecida de tal forma que apele de forma exaustiva e não-redutiva apenas aos fenômenos naturais. (FLORIDI, 20I7, p 30)

A naturalização de nosso conhecimento do mundo seria, assim, filosoficamente trivial ou equívoca: "A naturalização do não-natural resulta ser uma expressão da natureza artefactual do natural. Ironicamente, a naturalização é realmente uma semântica de segunda ordem". Floridi (2017, p 31).

Esse caráter artefactual do natural, pela vinculação das semânticas fenomênicas aos instrumentos de captura, processadores, meios de transmissão e de registro, é um aspecto importante que deverá ser incluído nessas reflexões.

\begin{abstract}
A ciência contemporânea parece estar presa em uma estranha situação. Por um lado, mantém um compromisso firme e razoável com uma metodologia naturalista saudável, segundo a qual as explicações dos fenômenos naturais nunca devem ultrapassar os limites do próprio natural. Por outro lado, a ciência contemporânea também está inextricavelmente e agora inevitavelmente dependente de tecnologias cada vez mais complexas, especialmente tecnologias de informação e comunicação, que explora e promove. No entanto, essas tecnologias estão cada vez mais "artificializando" ou "desnaturalizando" o mundo, as experiências e interações humanas, bem como o que se qualifica como real. Assim, a busca da explicação final do natural parece confiar em e promover o desenvolvimento do artificial, visto aqui como uma instanciação do não-natural. (FLORIDI, 20I7, Tradução e grifo nosso).
\end{abstract}

O construcionismo (a diferença do construtivismo) busca entender essa interdependência entre episteme e texné, numa concepção demiúrgica do homem, aquele que concebe algo, a partir de um outro algo que ele encontra já sendo, como mundo.

Com diferentes linguagens, Latour (2001) e Floridi (2017) direcionam a atenção para a precariedade explanatória dos dualismos, contrapondo theoria e texné, ontologia e epistemologia. Na sua abordagem semiótico- 
antropológica, Latour (2001) elabora o conceito de referência circulante, onde o termo referência designa o referente existencial de heterogêneas cadeias enunciativas que, como os jogos de linguagem de Wittgenstein, implicam uma composição de instancias materiais e simbólicas, humanas e não-humanas. A referência circulante é um modo de eliminar fronteiras radicais entre natureza e cultura, episteme e ontologia. Assim, o referente é capturado porque é transformado, mas referente e enunciado são co-construídos em trabalhosos processos de translação.

Se mantermos o princípio da correspondência entre as leis físicas e a coisa observada, não ficaria uma "folga" epistêmica para aquela "semântica de segunda ordem" que, conforme Floridi, constitui as descrições da natureza mediada pelos radiotelescópios, os algoritmos dos big data, e também pelos artigos dos periódicos científicos, as bases de dados referenciais e os índices de citação.

A proposta de Small, não alheias ao realismo crítico, segue outras trilhas epistemológicas. Uma delas, o leva a substituir da teoria da verdade como correspondência, por uma teoria coerêntista da verdade, pela qual a consistência entre teoria e o mundo, só pode estabelecer-se em redes de múltiplos fatos e previsões, onde as malhas se encaixam num quebracabeça maior, assim como " a teoria quântica do átomo também é consistente com o espectro eletromagnético do átomo e a natureza quântica da luz" (SMALL, 2016).

As escolhas argumentativas de Small visam sempre a preencher dois objetivos: consolidar as premissas de um realismo epistemológico não-ingenuo, e ancorar suas novas cartografias da ciência em premissas epistemológicas e historiográficas que garantissem suficiente flexibilidade, além de justificação.

As teorias da consiliência pareciam adequadas a essa finalidade, na medida em que, por analogia, os enunciados singulares de um artigo de periódico ficassem inseridos em extensas teias trans-discursivas, protegidas pela suposição que essas teias reconstroem as redes de teorias e fatos, palavras e empiria, e não são meras representações de representações. Essas teorias da consiliência (WILSON,1999) ou teorias coerêntista da verdade (THAGARD, 2007), precisariam justificar, ainda, o que valida os critérios conforme aos quais certas vinculações (e não outras) direcionam a demarche da ciência. Para identificar esses princípios preferenciais de orientação e justificação dos rumos seletivos da ciência, Small recorre à revisão das teorias normativas de Merton $(1938,1973)$.

Merton associa num mesmo arcabouço normativo, as normas éticas, reguladoras dos comportamentos sociais e profissionais dos cientistas e as normas técnicas, reguladoras da produção lógica e metodológica dos conhecimentos. Para Small, o problema seria que as teorias normativas da ciência são falhas em sua capacidade explanatória, na medida em que carecem de um olhar reflexivo sofre a própria natureza e genealogia das normas: “O problema com as normas técnicas e sociais é que elas parecem sair do nada, embora os primeiros escritos de Merton (1938) sugerem uma possível ligação com os valores puritanos detidos por muitos membros da Royal Society no século XVII. (SMALL, 2016, p 57; tradução nossa).

Um dos traços genealógicos das normas técnicas, analisados por Small, seria sua variabilidade, concordando com Zukerman (1977, p.122), sobre a carência de uma validade atemporal e irrestrita das mesmas. A norma científica do universalismo, por exemplo, poderia ter seu origem numa demanda de critérios de validação da ciência além das fronteiras geopolíticas, devido ao surgimento e expansão das "ciências nacionais", na Europa segmentada pelo tratado de Westfalia (SMALL, 2016, p 58). Com esse entendimento, as normas estariam vinculadas a usos bem-sucedidos, e poderiam surgir como "reação a novas realidades sociais".

Se as normas e suas sanções variam em peso e qualidade, a norma da honestidade seria da maior hierarquia, já que sua violação, ou fraude, além de poder acabar com a carreira do pesquisador, aniquilaria o regime de confiança que seria a base da expansão indefinida das interações dos coletivos da pesquisa. Afetaria, aliás, a pressuposição de validade metodológica das experiências baseadas num testemunho ocular (SMALL, 2016, p 59). Small depositaria no arcabouço normativo a principal conexão entre o Laboratório e o artigo científico: a norma da honestidade seria como um solo éticoepistêmico, onde ancorar a credibilidade das metodologias, incluídas as informétricas. São as normas que garantem o regime de confiança, sem o qual desmoronaria todo o sistemas de 
credibilidade da ciência. Sendo que as normas são, porém, variáveis, será necessária uma garantia adicional que estabelecese um nexo duradouro entre os artigos de periódicos e os conhecimentos científicos. A "norma da generosidade do referenciamento" (SMALL, 2016), proporcionaria esse princípio de confiabilidade, por sua emergência em processos evolutivos.

A instituição da referência, para Small, trabalha na construção de um nicho social para alocar uma ideia, e serve para reivindicação da autoria, desencorajar o plágio e deixar disponível, para futuras críticas ou aplicações, um conhecimento legitimado. A referência seria assim um operador funcional de um modo de produção social de conhecimentos, e uma testemunha da cooperação científica. As convenções bibliográficas e editoriais, além de demarcar o espaço discursivo da escrita científica, garantem a reciprocidade de expectativas dos participantes do jogo das citações e referências: instituídas na vigência de um regime de confiança, que hoje estaria em risco, e sendo substituído pelos regimes de accountability.

Para Small (2016), sem o arcabouço normativo que institui um regime de confiança, a escrita científica não se diferenciaria da literatura ficcional ou autobiográfica, levando a desaparecer referências e revisões da literatura, que são hoje os operadores da vinculação social e contextual da pesquisa. Sem essa vigência normativa dos operadores vinculantes, se perderiam também os compromissos que sustentam a responsabilidade dos autores.

Nesse quadro, as referências dão visibilidade a variabilidade histórica das normas técnicas; uma genealogia das referências e das revisões da literatura, através do estudo histórico dos periódicos científicos, seria um dos caminhos para a compreensão do funcionamento das normas na produção do conhecimento científico.

Existiria, porem, uma "área cinzenta entre a interpretação legítima e a distorção (SMALL, 2016), mas mesmo nesse caso, as diversas interpretações possíveis de um texto, seriam à posteriori da citação autoral, logo, a posteriore de uma relação direta do autor de um texto e o autor da citação. Desse ato autoral e originário, que involucra o citado na citação, Small infere o compartilhamento de uma produção de sentido. Desse modo, um alto índice de citações de um texto e autor, indicaria que o significado do artigo citado é compartilhado por um número crescente de citantes, originando um processo de construção de consenso. $O$ texto altamente citado funciona como atrator organizador da formação de um consenso coletivo.

Como sustentar, agora, que a pesquisa constitua núcleos de práticas sociais colaborativas e orientadas (direta ou indiretamente) à formação de zonas de consenso interpretativo, frente aos modelos e estratégias concorrenciais da atividade científica que, em termos de citações, se manifesta como hipótese da "vantagem cumulativa": o número de citações futuras depende da quantidade já acumulada (NEWMAN, 2010). Small cita, entre outros, a Hagstrom(1974), e sua abordagem do uso interessado da citação, sendo que os pesquisadores lutam entre sim pela a obtenção de prioridade, reconhecimento $e$ financiamento (HAGSTROM, 1974, POR SMALL, 2016).

È para fazer frente às teorias concorrenciais do desenvolvimento científico, que Small apresenta o conceito de referência generosa, uma garantia de maior alcance para sua teoria das citações. As práticas de citar e referenciar pertenceriam aos modos sociais de produção de cooperação e de consenso. As redes de co-citações seriam instrumentos de construção de coletivos (virtuais) de entendimento, onde a geração de relações indiretas (via médios), não descartaria alguma forma de relação intencional (consensual) da produção intersubjetiva do conhecimento científico. O aval epistêmico da citação será a cooperação, como comportamento intencional e altruísta dos agentes da atividade científica.

De fato, Small apresenta uma alternativa diferente ao debate contemporâneo sobre o caráter estratégico e concorrencial da atividade científica, seja dentro do regime neoliberal da economia de mercado, seja conforme as políticas internacionais de alianças e prioridades entre agências, países, blocos, regiões. E, certamente, frente as teorias da cooperação sem consenso (STAR, 1993).

Como afirmar, nesse quadro, a generosidade da referência? E como fazê-lo, preservando as hipóteses realistas e naturalistas sobre o conhecimento científico? Para Small, uma resposta seria que tanto a cooperação como a concorrência seriam ubíquas nas sociedades humana; de fato, o comportamento de quem 
cita teria sempre alguma ambiguidade. A escolha de citar ou não citar tem duas fases, já que ao referenciar damos crédito a outros, com um pensamento próximo ao nosso, mas ao mesmo tempo, citamos para diferenciar nossa contribuição, evitando as "sanções negativas" por não citar um trabalho relacionado ao nosso. "Assim, existe ambiguidade em afirmar se referenciar é um ato egoísta ou generoso" (SMALL, 2017, p 64, tradução nossa). Para Small, porem, existem condicionamentos de curto e médio prazo, compatíveis com teorias evolutivas. Se os pesquisadores singulares podem assumir papeis egoístas ou cooperantes, os jogos das citações gerariam regras pelas quais, aqueles agentes que seguem a regra forte de reciprocidade e citam outros, também "punem" os que violam a regra. E esse jogo de regras propiciaria, para Small, os condicionamentos de uma ciência evolutiva. Os comportamentos cooperativos (ou colaborativos, num sentido mais amplio) seriam plausíveis principalmente se olharmos não casos singulares de pesquisa, mas o desenvolvimento dos grupos e redes de pesquisa nos longos prazos.

\section{NOVOS PONTOS DE PARTIDA}

Nos perguntamos se é possível pensar que a análise de citações, uma das principais fornecedoras de insumos de validação dos indicadores de desempenho, estaria colaborando na construção algorítmica de um meta-autor dos discursos da ciência. A "ancoragem" da citação num espaço discursivo normativamente estabilizado (o artigo científico), obtém o reforço formal e institucional da referência, referendada pelas informações cadastrais.

Nos perguntamos se nesse nicho institucional de uma ideia, não acontece ao memso tempo um efeito de deslocamento da autoridade científica. De fato, a autoridade autoral da citação ficaria subsumida na autoridade institucional da referência, e sobre-determinada pelas técnicas intelectuais, computacionais e gerenciais da indexação. Podemos pensar que através da dupla operação da escrita científica e a sobrescrita da indexação, fica constituído um novo espaço de objetivação, experimentação e autorização da validade científica: onde a composição, seletiva e propositiva, de um corpus de citações e referências, geraria ao menos uma sombra discursiva pós-autoral

A base de dados do Science Citation Index teria gerado, por primeira vez, essa nova camada de objetivação da produção científica, que vai ganhando independência de seus agentes e processos diretos de produção, ao reconfigurar informações de diferente origem (citações e referências de artigos publicados numa extensa população de periódicos científicos) num novo artefato bibliográfico. Pensado como auxiliar da pesquisa acadêmica e historiográfica, o Science Citation Index abria espaço a toda uma geração de instrumentos de controle e monitoramento, com novos funcionamentos nas esferas da gestão científica e em empreendimentos informacionais de caráter lucrativo.

Caso análogo encontramos nos museus de história natural, onde hoje as coleções de espécimes biológicos se desdobram em novas "coleções digitais" -de tecidos e ADN-, gerando assim uma nova ordem de valores, públicos ou patrimoniais (SILVA, 2016). De modo equivalente, as citações textuais realizadas em artigos publicados em periódicos científicos, e nos quais as citações, como atos autorais, vinculam diretamente pesquisadores e enunciados, possuem condições de produção e geram condições de interpretação diferenciadas daquelas próprias dos agregados associativos de referências e citações (assemblages) nas grandes bases de dados indexadas, como as que sustentam o Science Citation Index, hoje os produtos e serviços da Web of Science, ou da base de dados Scopus-Elsevier.

Conforme problematizado por Kuhn e rebatido por Small, toda reconstrução informacional das formações coletivos da pesquisa científica, tem sempre acoplada a seus conjuntos inventariados de casos de inclusão, um conjunto complementar de casos de exclusão, para os quais, em princípio, carecemos de meios de computação e cálculo. Isso acontece com as grandes bases de dados, com modelos e procedimentos da Webmetria, e terá que ser debatido, em direção equivalente, nas novas experiencias das altmetrias.

Entre outros aspectos, é bom lembrar que hoje os arcabouços reguladores da ciência, são mais complexos que os reconstruídos por Merton e Zuckerman. Basta pensar que, além dos critérios e quadros normativos que hoje motivam 
(ou não) aos pesquisadores e especificam a imputabilidade dos sistemas de avaliação e de responsabilização, na esfera da pesquisa, existem outras instancias que lidam, antes que com normas, com a formalização do padrão.

A padronização, legitimação e variação das normas técnicas, que incluem os padrões bibliográficos, expressão em sua origem num ato autoral, são hoje objeto de uma complexa distribuição entre a modelização tecnológica que envelopa as normas em regras de infraestrutura, e as agências reguladoras de amplio escopo e abrangência, especializadas na sistematização e gestão de padrões, nacionais e internacionais (como a ISO- International Standard Organization, e a ABNT - Associação Brasileira de Normas Técnicas).

Considerando que ações de informação são ações sociais, pensamos que um dos legados das reflexões dos pioneiros das análises de citações, é sua problematização do papel das normas, e da genealogia das normas, nos processos de validação e formação de consenso, naquela tríade que entrelaça os sistemas de produção e comunicação dos conhecimentos, os sistemas de avaliação e responsabilização, e as ações e regimes de informação.

Nos permitimos retomar, a partir das reflexões de Small, e como assunto atual de preocupação, qual é a equação dos processos de validação orientados a formação de consenso ou conforme as teorias da coordenação sem consenso de ações coletivas, garantida pela eficácia dos meios, não somente na esfera da produção científica, mas em todas as modalidades de mediação informacional da formação dos discursos públicos.

Artigo recebido em 31/05/20I7 e aceito para publicação em I0/07/2017

\title{
CITATION ANALYSIS, NEED A THEORY OR PHILOSOPHY OF SCIENCE?
}

\begin{abstract}
This work, with epistemological orientations, aims to reconstruct the search for theoretical explanation of informetrics methodologies, according to the approach of the pioneers of theories of citation and cocitation. We consider that this self-reflection, confronting different theoretical alternatives, has signaled important questions that can renew our research priorities, in the current crossroads of information studies.
\end{abstract}

Keywords: $\quad$ Citations Analysis. Small. Paradigms. Constructivism. Norms.

\section{REFERÊNCIAS}

FLORIDI, Luciano. A defence of constructionism: Philosophy as conceptual engineering. Metaphilosophy, Hoboken, v. 42, n. 3, p. 282304, Apr. 2011.

GARFIELD, Eugene. Citation indexes for science. A new dimension in documentation through association of ideas. International journal of epidemiology, Oxford, v. 35, n. 5, p. 1123-1127, Bim. 2006.

GARFIELD, Eugene. From citation indexes to informetrics: is the tail now wagging the dog? Libri, Berlin, v. 48, n. 2, p. 67-80, June 1998.
_ Citation indexes for science: A New Dimension in Documentation through Association of Ideas. Science, New York, v. 122, n. 3159, p. 108-111, July 1955.

KUHN, Thomas. The structure of scientific revolutions. Chicago: University of Chicago Press, 1962.

LAMONT, Michèle. Em direção a uma sociologia comparativa da valoração e da avaliação. Novos Rumos Sociológicos, Pelotas, v. 1, n. 1, p. 7-37, jan./jun. 2013.

LATOUR, Bruno. Referência circulante: amostragem do solo da floresta amazônica. In: 
LATOUR, Bruno. A esperança de Pandora. Bauru: Edusc, 2001. p. 39-96.

LATOUR, Bruno. Science in action: how to follow scientists and engineers through society. Cambridge: Harvard University Press, 1987.

MERTON, Robert King. Foreword. In: GARFIELD, Eugene. Citation indexing: Its theory and application in science, technology, and humanities. New York: Wiley, 1979. Disponível em: <http://www.garfield.library. upenn.edu/cifwd.html>. Acesso em: 20-04-2017.

RIJCKE, Sarah de; WOUTERS, paul F.; RUSHFORTH, Alex D.; FRANSSEN, Thomas P.; HAMMARFELT, Börn. Evaluation practices and effects of indicator use-a literature review. Research Evaluation, Oxford, v. 25, n. 2, p. 161-169, abr. 2016.

SMALL, Henry G. Cited documents as concept symbols. Social studies of science, Thousand Oaks, v. 8, n. 3, p. 327-340, Aug. 1978.

SMALL, Henry. Co-citation context analysis and the structure of paradigms. Journal of documentation, Bingley, v. 36, n. 3, p. 183-196, Sep. 1980.

SMALL, Henry. Paradigms, citations, and maps of science: A personal history. Journal of the American Society for Information Science and Technology, New York, v. 54, n. 5, p. 394-399, Mar. 2003.

_. Referencing as cooperation or competition: Citation process revisited. In: SUGIMOTO, Cassidy R. (Ed.). Theories of informetrics and scholarly communication. De Gruyter, 2016. p. 49-71.

STAR, Susan Leigh. Cooperation without consensus in scientific problem solving: Dynamics of closure in open systems. In: EASTERBROOK, Steve (Ed.). CSCW: Cooperation or Conflict? London: Springer Verlag, 1993. p. 93-106.

SUGIMOTO, Cassidy R. (Ed.). Theories of informetrics and scholarly communication. Walter de Gruyter GmbH \& Co KG, 2016.

Introduction. In: SUGIMOTO, Cassidy R. (Ed.) Theories of informetrics and scholarly communication. Walter de Gruyter, 2016. p 1-9.

THAGARD, Paul. Coherence, truth, and the development of scientific knowledge. Philosophy of science, v. 74, n. 1, p. 28-47, Jan. 2007.

WILSON, Edward O. Consiliência: a unidade do conhecimento. Rio de Janeiro: Campus, p. 174, 1999.

WITTGENSTEIN, Ludwig. Investigações filosóficas. Rio de Janeiro: Ed. Vozes, 1994.

WOUTERS, Paul, The Citation: From Culture to Infrastructure. In: CRONIN, Blaise; SUGIMOTO, Cassidy (Ed.). Beyond Bibliometrics: HarnessingMultidimensional Indicators of Scholarly Impact. Cambridge: MIT press, 2014. p. 47-66.

Beyond the holy grail: from citation theory to indicator theories. Scientometrics, Budapest, v. 44, n. 3, p. 561-580, Mar. 1999. 